\title{
Acquired Hyperzincaemia Due to Zinc-Laden Denture Adhesives Leading to Hypocupraemia as a Cause of Neutropenia
}

\author{
FNU Amisha $^{1}$, Prachi Saluja ${ }^{1}$, Nitesh Gautam ${ }^{1}$, Shubham Biyani², Sunilkumar Kakadia ${ }^{3}$ \\ 1. Department of Internal Medicine, University of Arkansas for Medical Sciences, Little Rock, Arkansas, United States \\ ${ }^{2}$ Department of Neurology, University of Arkansas for Medical Sciences, Little Rock, Arkansas, United States \\ ${ }^{3}$ Hematology/Oncology Division, Department of Internal Medicine, University of Arkansas for Medical Sciences, Little Rock, Arkansas, United States
}

Received: 08/10/2021

Accepted: 30/10/2021

Published: $29 / 11 / 2021$

How to cite this article: Amisha FNU, Saluja P, Gautam N, Biyani S, Kakadia S. Acquired hyperzincanemia due to zinc-laden denture adhesives leading to hypocraemia as a cause of neutropenia. EJCRIM 2021;8: doi:10.12890/2021_002983.

Conflicts of Interests: The authors declare there are no competing interests.

This article is licensed under a Commons Attribution Non-Commercial 4.0 License

\section{ABSTRACT}

Introduction: Copper deficiency or hypocupraemia is a rare cause of anaemia and neutropenia.

Case description: We hereby present the case of a 34-year-old female with gastric bypass surgery who presented with neutropenic fever, abdominal pain and diarrhoea, later found to have extended-spectrum beta-lactamase resistant Escherichia coli urinary tract infection and small bowel bacterial overgrowth syndrome, with her anaemia and neutropenia being caused by copper deficiency due to hyperzincaemia induced by using zinc denture adhesive cream.

Discussion: Various causes of copper deficiency have been recognized including, but not limited to, malnutrition, gastrectomy, gastric bypass surgery, protein-losing enteropathies (coeliac disease, tropical sprue), Wilson disease and Menkes syndrome. Copper deficiency caused by zinc overuse is not very prevalent. The haematologic abnormalities associated with copper deficiency are neutropenia, sideroblastic anaemia and/or pancytopenia.

Conclusion: Because of its low prevalence and nonspecific haematologic and clinical manifestations, the diagnosis of zinc-induced copper deficiency (ZICD) can be missed.

\section{LEARNING POINTS}

- Zinc toxicity is a rare cause of hypocupraemia.

- The bone marrow and haematological manifestations of copper deficiency are not pathognomonic but include sideroblastic anaemia, pancytopenia or neutropenia.

- Early detection of hypocupraemia as a cause for neutropenia will improve morbidity and mortality by avoiding untoward infections due to neutropenia, neurological decline or unnecessary interventions.

\section{KEYWORDS}

Zinc toxicity, pancytopenia, copper deficiency, anaemia, neutropenia

\section{CASE DESCRIPTION}

A 34-year-old Caucasian female presented to our hospital for worsening fever $\left(38.8^{\circ} \mathrm{C}\right)$ and epigastric pain - dull, aching, non-radiating, nonpositional. Prior to presentation, she had been having low-grade fever (38.0-38.1. ${ }^{\circ} \mathrm{C}$ ), nausea and vomiting, generalized weakness, loose stools - non-bloody, approximately 5 times per day and unintentional weight loss (approximately $4.5 \mathrm{Kg}$ ) over the previous 4 weeks. Her haemoglobin and white blood cell counts were found to be decreasing over the last 8 weeks despite using oral iron supplementation and 
she was started on levofloxacin for neutropenic prophylaxis 2 weeks previously when her absolute neutrophil count was 410 cells/ $\mu$ l. Her other medical history included Roux-en-Y gastric bypass surgery 15 years previously, cholecystectomy 4 years previously, mood disorder, iron deficiency anaemia and peptic ulcer disease. She reported no food preferences, was eating a regular diet and worked as a clerk with sufficient income to sustain a healthy lifestyle. She denied chills, night sweats, weight change, cough, chest discomfort, haematochezia, melena, haematemesis or easy bruising, alcohol or illicit drug use, herbal supplements.

On physical examination, there was pallor and dentures with some gum swelling. Initial laboratory investigations are described in Table 1. Chest imaging was unremarkable.

\begin{tabular}{|c|c|c|}
\hline Investigation & Value & Reference range \\
\hline \multicolumn{3}{|l|}{ Haemogram } \\
\hline Haemoglobin (g/dl) & 9.7 & $13-17$ \\
\hline WBC K/Ml (N/L/M/E/B \%) & $1.72(17.3 / 63.4 / 13.4 / 4.7 / 0.6)$ & 3.6-9.5 (35-65/23-50/4.6-12/0.5-6.5/0.1-1.1) \\
\hline Platelets (K//l) & 232 & $150-450$ \\
\hline MCV (fl) & 87.9 & $80-100$ \\
\hline $\mathrm{MCH}(\mathrm{pg})$ & & $26-33$ \\
\hline $\mathrm{MCHC}(\mathrm{g} / \mathrm{dl})$ & & $32-36$ \\
\hline Absolute neutrophil count & 300 & $>1,500$ cells $/ \mu \mathrm{l}$ \\
\hline \multicolumn{3}{|l|}{ Renal chemistry } \\
\hline $\mathrm{Na} / \mathrm{K} / \mathrm{Cl} / \mathrm{CO} 2(\mathrm{mmol} / \mathrm{l})$ & $135 / 3.7 / 102 / 25$ & $135-145 / 3.5-5.1 / 98-107 / 22-32$ \\
\hline $\mathrm{BUN} / \mathrm{Cr}$ (mg/dl) & $13 / 0.7$ & $6-20 / 0.6-1.3$ \\
\hline \multicolumn{3}{|l|}{ Liver function test } \\
\hline AST/ALT (IU/I) & $502 / 244$ & $15-41 / 4-45$ \\
\hline GGT (IU/I) & 249 & $7-50$ \\
\hline $\mathrm{LDH}(\mathrm{IU} / \mathrm{I})$ & 284 & $100-248$ \\
\hline Alk phos (IU/I) & 294 & $32-91$ \\
\hline Bilirubin, total (mg/dl) & 0.6 & $0.2-1.2$ \\
\hline \multicolumn{3}{|l|}{ Miscellaneous } \\
\hline Retic count & 1.2 & \\
\hline Folate & 16.21 & $>22.3 \mathrm{ng} / \mathrm{ml}$ \\
\hline Vit B12 & 395 & $180-914 \mathrm{pg} / \mathrm{ml}$ \\
\hline Ferritin & 26.3 & $10-300 \mathrm{ng} / \mathrm{dl}$ \\
\hline Total iron binding capacity & 235 & $250-425 \mu \mathrm{g} / \mathrm{dl}$ \\
\hline Iron saturation & 22 & $15-50 \%$ \\
\hline Amylase & 25 & $28-100 \mathrm{U} / \mathrm{I}$ \\
\hline Lipase & 10 & $13-60 \mathrm{U} / \mathrm{I}$ \\
\hline
\end{tabular}

Table 1. Inital laboratory investigations on admission 
Computed tomographic imaging of the abdomen/pelvis showed hepatic steatosis, no bile duct dilatation, a dilated small bowel loop that could be the focus of ileus vs elements of obstruction. Ultrasound of the abdomen and magnetic resonance imaging of the abdomen showed fatty infiltration of the liver. Oesophagogastroduodenoscopy (OGD) revealed a normal stomach, oesophagus and afferent limb with inability to intubate the efferent limb of the jejunum. Upper gastrointestinal (UGI) series showed contrast passing through the efferent limb with no evidence of gastric outlet obstruction. Repeat OGD after 3 days with colonoscopy showed normal mucosa with jejunal biopsy revealing focal active inflammation with mild villous blunting and crypt hyperplasia. A liver biopsy was carried out which showed macrovesicular steatosis, negative iron or trichrome staining. Secondary causes of elevated liver enzymes, infectious (viral - hepatitis, human immunodeficiency virus, Epstein-Barr and cytomegalovirus), autoimmune disease (coeliac, autoimmune hepatitis, immunoglobulin deposition, primary biliary cirrhosis), toxins (alcohol, salicylates), metabolic (serotonin syndrome, porphyrins), infiltrative (Wilson, alpha-1 antitrypsin deficiency, haemochromatosis) were ruled out. A diagnosis of small intestinal bacterial overgrowth syndrome (SIBO) and non-alcoholic steatohepatitis (NASH) was made.

To further evaluate the cause of the patient's worsening bicytopenia, more studies were conducted. A peripheral smear showed normocytic anaemia with anisopoikilocytosis with microcytes, macro-ovalocytes, polychromatic cells as well as mild leucopenia with absolute neutropenia and relative lymphocytosis with few large granular lymphocytes; negative for myelocytes or myeloblasts. Bone marrow biopsy and aspiration showed hypocellular marrow with 35\% cellularity, with left-shift granulocytic maturation, myeloid:erythroid ratio 1:2, absent iron stores and no morphologic evidence of lymphoma, myelodysplasia, infiltrative disease or granulomas. Cytogenetic analysis showed the normal female karyotype $(46, \mathrm{XX})$ with no evidence of myelodysplastic syndrome in fluorescence in situ hybridization examination. On Day 5 of admission, urine culture became positive for extended-spectrum beta-lactamase resistant Escherichia coli.

Based on the patient's diagnosis of SIBO and past history of gastric bypass with hypocellularity in bone marrow studies, we decided to test for trace micronutrients. She was found to have multiple micronutrient and vitamin deficiency, vit D 25-hydroxy 29.4 (30-100 ng/ml), vit E $1.6(5.5-18 \mathrm{mg} / \mathrm{dl})$ and vit A $0.17(0.30-1.20 \mathrm{mg} / \mathrm{dl})$. On further interview, she reported using zinc-based denture glue several times a day for the last few years due to ill-fitting dentures. Subsequent testing revealed an elevated plasma zinc level of $140 \mu \mathrm{g} / \mathrm{dl}$ (normal range $56-134$ $\mu \mathrm{g} / \mathrm{dl}$ ) and a markedly low plasma copper level of $10 \mu \mathrm{g} / \mathrm{dl}$ (normal 72-166 $\mu \mathrm{g} / \mathrm{dl}$ ), and caeruloplasmin of $8 \mathrm{mg} / \mathrm{dl}$ (normal 20-60 mg/dl). She was diagnosed with anaemia and neutropenia secondary to copper deficiency from zinc toxicity, possibly exacerbated by Roux-en-Y gastric bypass surgery 15 years previously and SIBO, which led to urinary tract infection with resistant Gram-negative bacilli.

For her neutropenic fever, she was initially started on broad-spectrum antibiotics with cefepime and vancomycin which was shifted to meropenem after the result from urine culture. For her SIBO, she was started on $100 \mathrm{mg}$ doxycycline twice daily for 7 days with a repeat 7-day course every third week for a total of 2 months. For her mineral and vitamin deficiency, she was started on copper gluconate 2 mg daily,

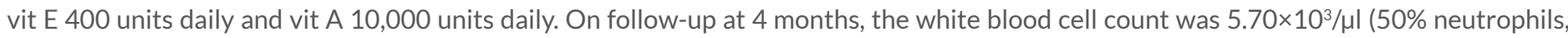
$39.1 \%$ lymphocytes, $8.9 \%$ monocytes, $1.1 \%$ eosinophils, $0.7 \%$ basophils), absolute neutrophil count was $2,850 / \mu l$, haemoglobin of $11.1 \mathrm{~g} / \mathrm{dl}$, mean corpuscular volume was $81.5 \mathrm{fl}$ and platelet count was $264 \times 10^{3} / \mu$ l with normal liver function test results (Fig. 1).

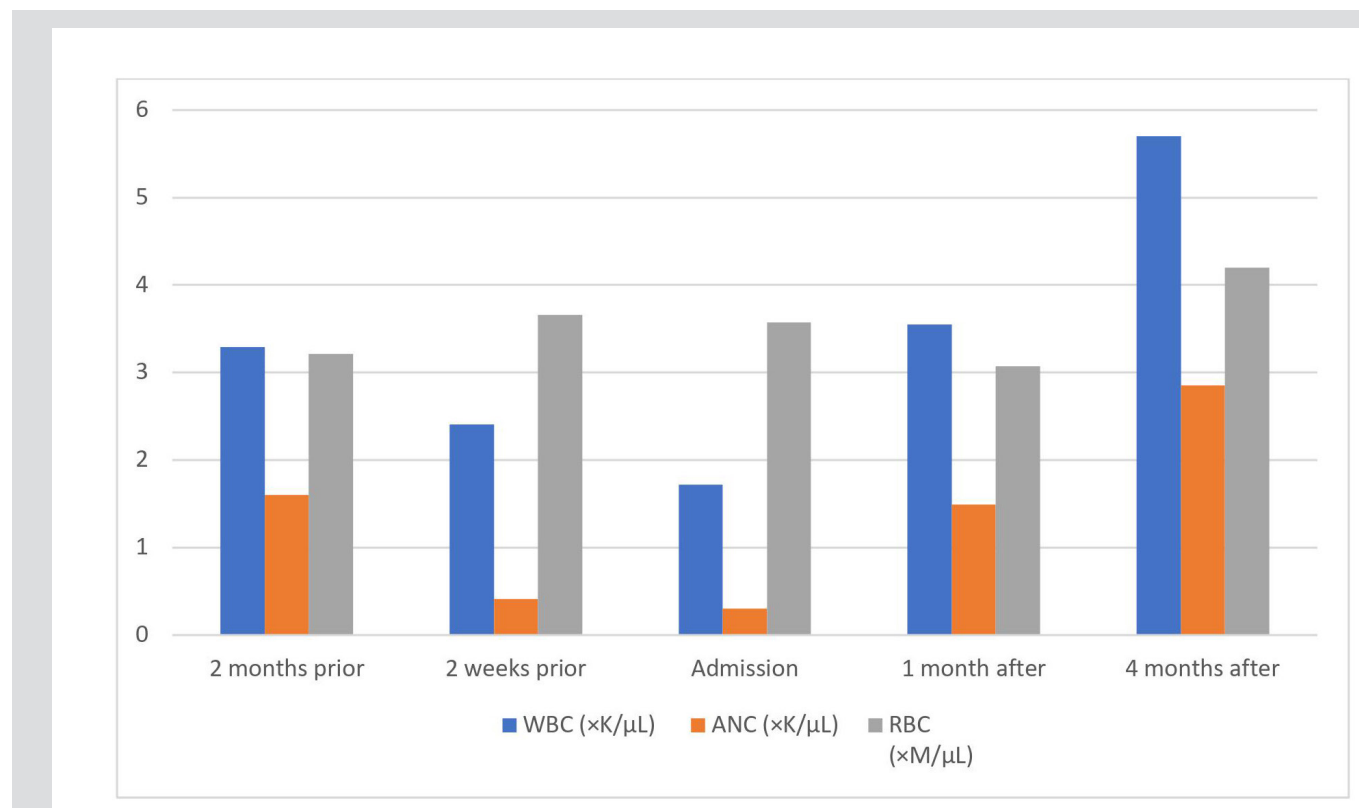

Figure 1. Evolution of white blood cell (WBC) count, absolute neutrophil count (ANC) and red blood cell (RBC) count from 2 months prior to hospital admission to 4 months after 


\section{DISCUSSION}

Copper is an essential trace element and is a common component of numerous metalloenzymes involved in haematopoiesis, in the structure and function of central nervous system and skeletal and vascular tissues and in the metabolism of catecholamines ${ }^{[1]}$. Acquired copper deficiency, or hypocupraemia, is an uncommon entity in healthy adults because of its widespread distribution in food and low daily requirements in adult humans ${ }^{[1]}$. Excessive zinc utilization in the form of topical, oral or enteral products such as acne creams, wound care products, over-the-counter zinc supplementation, therapeutic zinc use for glucagonoma, hepatic encephalopathy, decubitus ulcer healing or the common cold, denture adhesive creams and/or ingestion of zinc-containing metal objects have been implicated as potential causes of hypocupraemia.

The most common haematologic abnormality in copper deficiency is anaemia with leucopenia in the following frequencies: normocytic $>$ macrocytic >> microcytic ${ }^{[2-4]}$. Bone marrow evidence of copper depletion includes hypocellularity, vacuolization of myelocytes and promyelocytes, excessive iron in plasma cells and macrophages, ringed sideroblasts, erythroid and granulocytic hyperplasia ${ }^{[2-4]}$. Hypocupraemia has also been reported to cause irreversible demyelination within the central nervous system which does not improve with copper supplementation.

The exact details of the mechanism by which copper is absorbed from the diet are unknown but within physiological ranges of intake, it is usually absorbed in the small intestine with the help of the ATP7A protein on the basolateral surface of enterocytes ${ }^{[5]}$. With supraphysiological intake, another mechanism involving intracellular metallothionein (MTO) comes into play. MTO binds to transition metals (copper, zinc and cadmium), forming mercaptide bonds via multiple cysteine residues and MTO-bound metals get excreted in faeces through enterocyte shedding ${ }^{[6,7]}$. MTO synthesis is directly influenced by plasma zinc concentrations and the size of the intracellular zinc pool of the body. Excess zinc induces enterocytes to synthesize more MTO by increasing MTO gene expression; copper has greater affinity for MTO, and hence, competitively displaces zinc from its binding sites ${ }^{[0,7]}$. While zinc MTO has a half-life of $18-20$ hours, copper MTO is more durable and resistant to proteolysis but these mutually antagonistic effects are noted only with striking dietary imbalances in copper and zinc levels. This reduces copper delivery to enterocytes due to excessive excretion in faeces.

Copper deficiency leads to an arrest in RBC synthesis by affecting iron transport/utilization and leads to more RBC destruction, resulting in various haematologic abnormalities. Caeruloplasmin is required for conversion of ferrous iron (+2) to ferric iron (+3), allowing iron to bind to transferrin for its transport, and copper-dependent cytochrome $\mathrm{c}$ is required for reduction of ferric iron for incorporation within the heme molecule; deficiency of both leads to defects in heme synthesis ${ }^{[8]}$. Furthermore, superoxide dismutase is reduced in the RBC membrane, decreasing RBC survival ${ }^{[9]}$. Copper deficiency causes ineffective myelopoiesis, a reduced number of progenitor cells, increased destruction of copper-depleted neutrophils and development of anti-neutrophilic antibodies ${ }^{[10]}$.

\section{REFERENCES}

1. Williams DM. Copper deficiency in humans. Semin Hematol 1983;20(2):118-128

2. Summerfield AL, Steinberg FU, Gonzalez JG. Morphologic findings in bone marrow precursor cells in zinc-induced copper deficiency anemia. Am J Clin Pathol 1992;97(5):665668.

3. Fuhrman MP, Herrmann V, Masidonski P, Eby C. Pancytopenia after removal of copper from total parenteral nutrition. JPEN J Parenter Enteral Nutr 2000;24:361-366.

4. Willis MS, Monaghan SA, Miller ML, McKenna RW, Perkins WD, Levinson BS, et al. Zinc-induced copper deficiency: a report of three cases initially recognized on bone marrow examination. Am J Clin Pathol 2005;123(1):125-131.

5. Kumar N, Ahlskog JE, Gross JB Jr. Acquired hypocupremia after gastric surgery. Clin Gastroenterol Hepatol 2004:2(12):1074-1079.

6. Kägi JH. Overview of metallothionein. Methods Enzymol 1991;205:613-626.

7. Webb M, Cain K. Functions of metallothionein. Biochem Pharmacol 1982 15;31(2):137-142.

8. Frieden E. The copper connection. Semin Hematol 1983;20(2):114-117.

9. Williams DM, Lynch RE, Lee GR, Cartwright GE. Superoxide dismutase activity in copper-deficient swine. Proc Soc Exp Biol Med 1975;149(2):534-536.

10. Brunning RD, Bennett JM, Flandrin G, Matutes E. Refractory anaemia with ringed sideroblasts. In: Jaffe ES, Harris NL, Stein H, Vardiman JW, editors. Pathology and genetics: tumours of haematopoietic and lymphoid tissues (World Health Organization classification of tumours). Lyon, France: IARC Press; 2001 , p. 69. 